\title{
An Investigation of Soil micro faunal diversity in chemical effluents contaminated soil versus normal soil at A. B. N. Seal College Campus, Cooch Behar, West Bengal
}

\author{
Debojyoti Dutta* \\ Dept. of Zoology, A. B. N. Seal College, P.O. \& Dt- Cooch Behar, PIN-736101, West Bengal, India \\ * Corresponding author: debojyotidutta2001@gmail.com, Tel-03582-226112 \\ Available online at: www.isroset.org
}

Received: 25/Sept/2019, Accepted: 15/Oct/2019, Online: 31/Oct/2019

\begin{abstract}
A B N Seal College, Cooch Behar is a 131 years old premier general Degree College of West Bengal. Since it is in Government premises, therefore there is not much alteration of soil type over here. Chemistry Department has its 47 years old glory. So, it is obvious that chemical effluents which are going directly into soil will be contaminated since the time of establishment of this Department. In this paper an attempts are undertaken to make a comparative analysis of Soil micro faunal diversity in chemical effluents contaminated soil versus normal soil at A. B. N. Seal College Campus, Cooch Behar, West Bengal. Here not only surface soil is considered but also different depth of the soil is also giving much importance as a parameter. All microscopical analyses are being done under 400X magnification with photographic attachment. Micro arthropod, mites and ants diversity in terms of number and species are varied from control site to experimental sites. Large number degenerated nematode eggs are found in upper surface of the experimental sites. Lesion nematodes were found in all the depths of the investigated soil. Depth below 6 to 12 inches, presence cysts of nematodes indicates adverse environmental condition for their sustainability.
\end{abstract}

Keywords- Nematodes, Mites, Cyst, Soil, Micro arthropod.

\section{INTRODUCTION}

Soil is a complex natural film discontinuously covering the Earth's surface that is not underwater. Soil can also be defined as an interface between the four main components: minerals, water air and organic matter (either living or dead) or in other words, the lithosphere, the hydrosphere, the atmosphere and the biosphere. The soil is important because of its interaction between its abiotic and biotic components, because of its action as a substratum of wild plants and crops, conveying the nutrients for the upper trophic levels in the life pyramid and because its biota is fundamental part of the unknown biodiversity.

\section{CLASSIFICATION OF SOIL FAUNA}

Soil fauna is abundant, rich and diverse. High numbers of individuals and species belonging to all terrestrial phyla can be found here (Rotifera, Annelida, Mollusca, Tardigrada and most of all Nematoda and Arthropoda).

Usually Arthropoda show the highest diversity, although there are accounts showing that they are probably equaled, if not surpassed, by the Nematoda (far less studied and
understood).Representatives of all the arthropodan subphyla and of all of their terrestrian classes can be found in the soil: Cheliceromorpha (scorpions, pseudoscorpions, spiders, harvestmen and mites, and other rarer groups), Crustacea (amphipods and woodlice), Myriapoda (centipedes, millipedes, and rarer groups), and Hexapoda (insects and close allies).

Nevertheless, apart from taxonomic classifications, some other kind of classifications based upon horizontal distribution or body size can be more useful for soil fauna. This classification on body size has widespread repercussions on sampling and study of the different groups. Most authors [1] differentiate three size classes: micro-, meso- and macrofauna.

However, there is a fundamental division in the sampling methods for micro-fauna and the other two groups (which are referred to as meso-fauna macrofauna) which solely base on their body sizes. The sampling methods have been discussed in the following. 


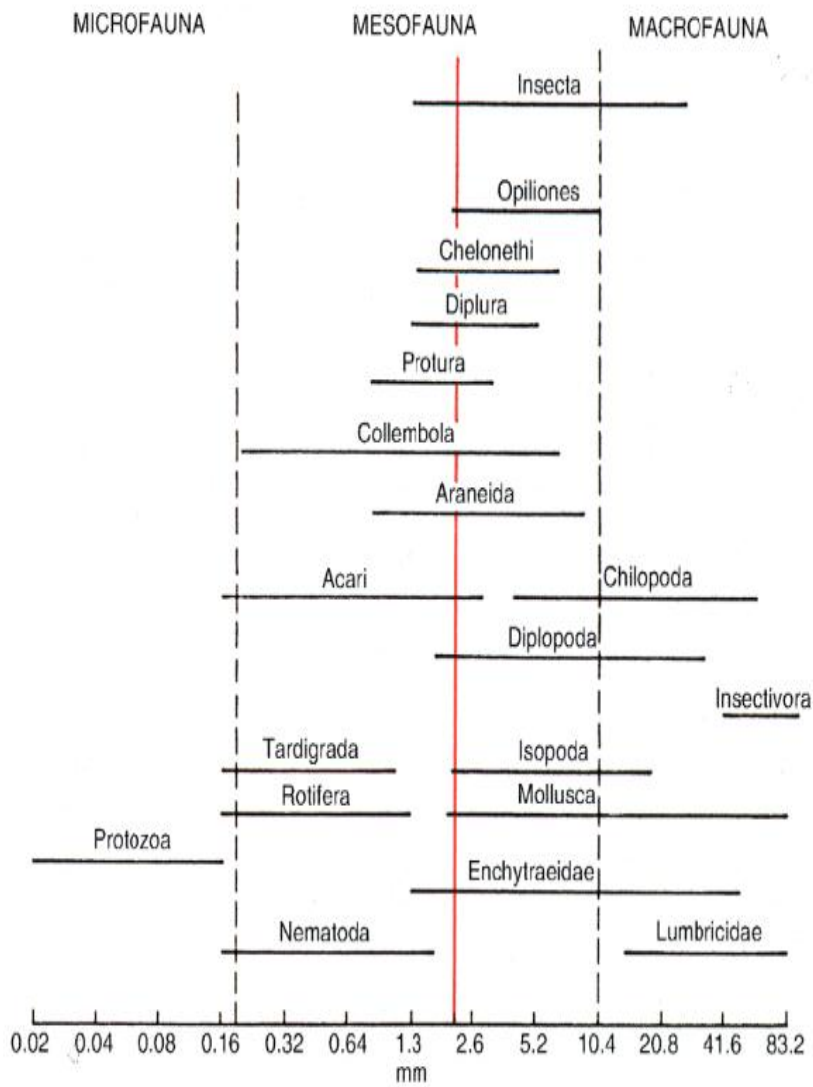

Fig 1 : Size classes in soil fauna groups, according to Wallwork (1976), modified to show the $2 \mathrm{~mm}$ boundary

(Black dense line) [1, with slight modification]

The present paper deals with investigation of soil micro faunal diversity with increasing depth (up to 1 feet) in chemical effluents contaminated soil versus normal soil at A. B. N. Seal College Campus, Cooch Behar, West Bengal.

\section{METHODOLOGY}

\section{(A) GPS Location of the collection spot:- \\ $>$ Control Soil collection spot:}

- GPS Location point : $89^{\circ} 27^{\prime} 0^{\prime \prime} \mathrm{E}$, $26^{\circ} 19^{\prime} 6^{\prime \prime} \mathrm{N}$

The spot is close to the spot of experimental setup but is not in contact with any time of chemicals. It represents soil texture, soil fauna without any external modification by chemicals.

\section{Dxperimental Soil collection spot:}

- GPS Location point: $89^{\circ} 26^{\prime} 58^{\prime \prime}$ E, 26 $6^{\circ} 19^{\prime} 18^{\prime \prime}$ 'N

The spot we chose was very near to the drain through which waste chemical effluents of the Chemistry Department were disposed of. The place is often in contact with a plethora of chemical compounds of various natures. So, it was a suitable spot for collecting soil samples.
(B) Selection of the minimum and maximum depth:

Minimum depth was selected as surface level i.e. soil was collected from soil surface. Maximum depth selected was 12 inches or 1 feet.

(C) Collection of soil samples (Hand picking) : Soil was dug up at specific place by use of soil digging tools. As we had only one Berlese funnel, the experiments had to be done separately for soil samples of each depth.

Approximately $1.5 \mathrm{~kg}$ soil sample was collected in a polythene bag and the bag was closed to prevent desiccation of the soil sample. The hole in the soil was then covered so that the hole was not filled with debris. The sample was taken to the lab, tagged with date and a hint of water was sprayed over the soil sample. It was then used for experiment and the rest was preserved as per [8]. This process was followed for each of the depth range soil was collected from.

(D) Preserving the Soil Sample: After discarding rocks found in the soil, it was put in a polythene bag, sealed and kept in locked (in dark) for further analysis (if any).Weight and volume were measured and keep in record. The soil samples weighed an average of $1.5 \mathrm{~kg}$ and volume of the sample was approximately $1.3 \mathrm{~L}$.

\section{(E) Tullgren Funnel Analysis:-}

$1230 \mathrm{~g}$ of soil from a particular depth (different depths of soil were experimented individually) was placed over the sieve in the Tullgren Funnel. Any lumps in the soil was broken and the soil was spread uniformly on the sieve of the funnel. Surface of the soil was approximately $3 \mathrm{~cm}$ away from the bulb for optimal heating of the soil sample. A 40-watt bulb was fitted on the funnel and turned on. The time was recorded duly. The whole apparatus was kept in dark for 21 hours. (3pm-12pm next day).With the rise of temperature and light intensity soil organisms move away from the soil surface (negative phototactic movement) and go downwards. As a result, organisms of appropriate size fall through the sieve into the Petri dish containing $70 \%$ alcohol (ethanol). The petridish is taken out from the apparatus after 21 hours and the alcohol containing the microorganisms are collected microfuge tubes for further examination under microscope. The tubes are marked according to depth of soil with date and time of collection.

\section{(F) Observation and Microphotography:-}

For observation a small drop of the sample (Stirred vigorously to discourage precipitation of the micro \& macrofauna) is placed onto a slide using a pipette without stain and observed under microscope with 400X magnification. (Model: Olympus CX33). Photographs of the fauna present in the sample are taken by a DSLR camera (Canon EOS 1200D) attached to the microscope using laptop (connected to the camera). 


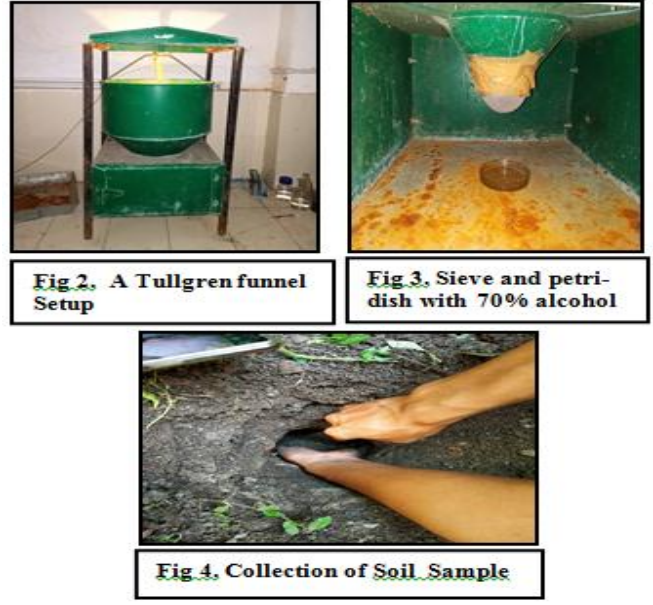

IV. RESULT AND DISCUSSION

In control site, surface soil is fully dominated by fragmented parts of Arthropod and nematode egg shell. Chelicerae legs are also noticed. At 6 inches depth mites and ants with appendages are also seen. At 12 inches soil sample are dominated by lesion nematode, micro arthropod and sting nematode. In experimental site (where chemical effluents are discharged by chemistry laboratory) surface soil having nematode egg with and without (or degenerated) egg shell. At 6 inches depth chain of eggs are also noticed. Surprisingly Dagger Nematode is also seen. At 12 inches depth Lesion Nematode and cyst Nematode are also seen. However for correct species identification Scanning Electron Microscopic Examination is requisite. The samples are sent for SEM analysis.
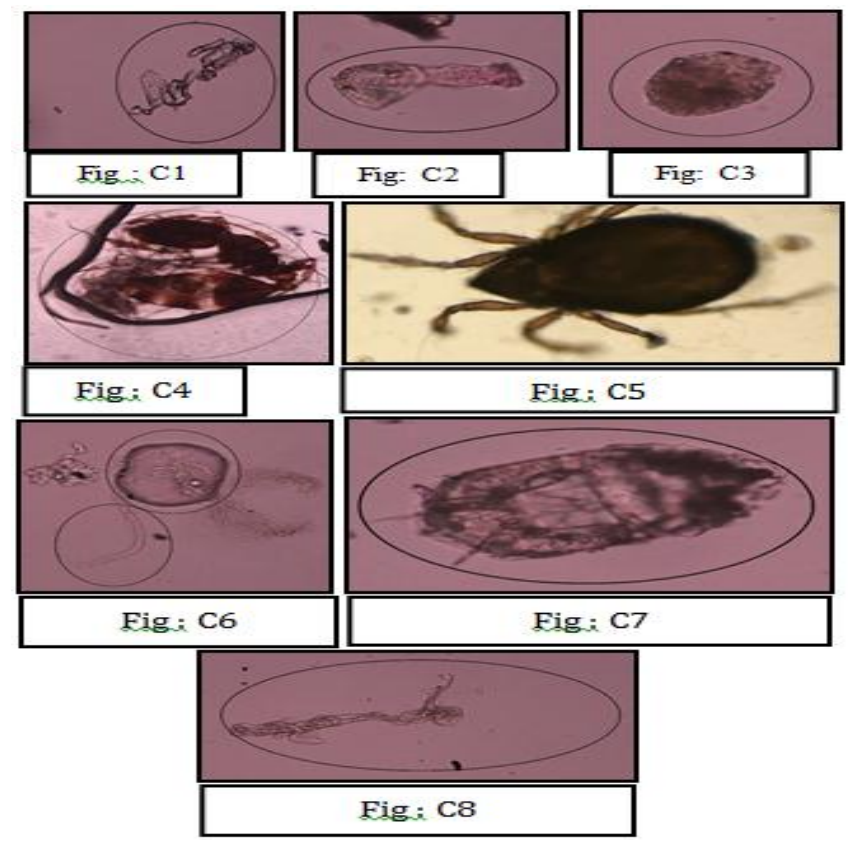

Fig.5. Microscopically view (under 400X) of different representatives in Control soil.
C1 - Leg \& other body parts of Arthropods, C2 -

Chelicerated leg of micro arthropod

C3 - Nematode egg with shell

(Note-C1, C2, C3 are found in Surface soil of the Control sites)

C4 - Ant with all appendages, C5 - Mite

(Note-C4, C5 are found in soil of 6 inches depth of the control site)

C6 - Lesion Nematode

C7 - Micro arthropod, C8 - Sting Nematode

(Note- C6,C7, C8 are found in 12 inches depth of the control site)

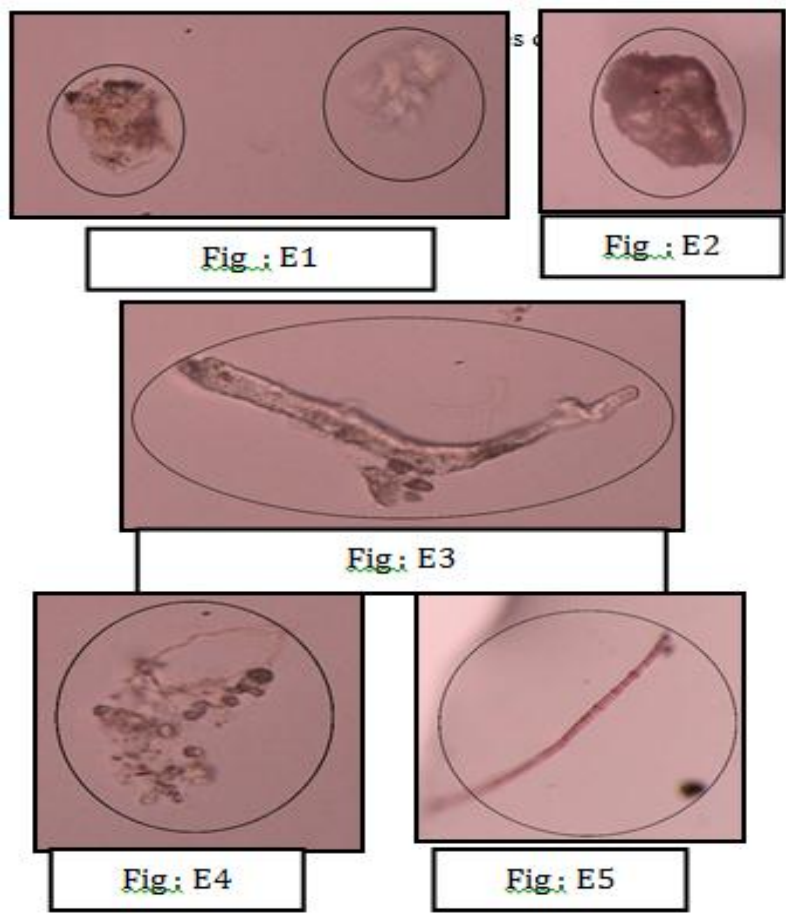

Fig.6. Microscopically view (under 400X) of different representatives in Experimental site soil.

E1\& E2 - Nematode eggs with \& without (degenerated) egg shell

(NoteE1 \& E2 are found in Surface soil of the Control sites E3 -Dagger nematode (Xiphinema sp.); E4 - Chain of eggs

( Note - E3 \& E4 are found in 6 inches depth of the experimental site)

E5 - Lesion Nematode; E2 - Cyst of Nematode

( Note - E2 \& E5 are found in 6 inches to 12 inches depth of the experimental site)

\section{CONCLUSION AND FUTURE SCOPE}

Chemistry Laboratory usually during practical with certain chemical and after doing it the glass good and apparatus are washed off. The effluents are in direct contact with soil. Table 1 represents commonly used chemicals in Chemistry 
laboratory for the partial fulfillment of their practical syllabus for both Core and Programme course on chemistry.

Table 1:- Commonly used chemicals effluents of Chemistry Laboratory of A. B. N. Seal College, Cooch Behar, West Bengal

\begin{tabular}{|l|l|}
\hline \multicolumn{1}{|c|}{ Observation \& Statement } & $\begin{array}{c}\text { References } \\
\text { Consulted }\end{array}$ \\
\hline $\begin{array}{l}\text { Salicylic acid reduces fecundity, growth \& } \\
\text { number of Cyst nematodes. }\end{array}$ & {$[2]$} \\
\hline $\begin{array}{l}1,3 \text { di-chloropropene acts as a nematicide for Sting } \\
\text { Nematodes. }\end{array}$ & {$[3]$} \\
\hline $\begin{array}{l}\text { Benzaldehyde, Salicyldehyde, Borneol, p- } \\
\text { anisaldehyde, cinnamaldehyde cause 50\% } \\
\text { mortality in test population of root-lesion } \\
\text { nematode Pratylenchus brachyurus. }\end{array}$ & {$[4]$} \\
\hline $\begin{array}{l}\text { Strong acids \& alkali destroy nematode eggs \& } \\
\text { reduce population of nematodes like root-knot } \\
\text { nematode in experimental conditions. }\end{array}$ & {$[5]$} \\
\hline $\begin{array}{l}\text { Diluted acids such as dil. Sulfuric acid, nitric acid } \\
\text { etc. (which mimics the chemical condition and } \\
\text { composition of acid rain) affects immature stages, } \\
\text { reduces fecundity, increases mortality rate in } \\
\text { different types of mites. }\end{array}$ & {$[6]$} \\
\hline $\begin{array}{l}\text { p-nitrophenol is very toxic to nematode } \\
\text { community. Total number of soil microarthropods } \\
\text { decrease by almost 50\% after application of } \\
\text { trinitrotoluene (200 } \mu \text { g/g) compared to control } \\
\text { (unaffected) population. Oribatid mite \& } \\
\text { prostigmatid mite population are affected the } \\
\text { most. }\end{array}$ & {$[7]$} \\
\hline
\end{tabular}

Extensive literature survey based on effects of chemicals on soil micro arthropod diversity clearly reveals the following conclusion related to effect of different chemicals. The observation statement \& their references are tabulated in table 2. .

Table 2:-Effect on laboratory chemical on soil micro arthropod diversity.

\begin{tabular}{|l|l|}
\hline \multicolumn{1}{|c|}{ Name of Chemical } & \multicolumn{1}{c|}{ Formula } \\
\hline Salicylic Acid & $\mathrm{C}_{6} \mathrm{H}_{4}(\mathrm{OH}) \mathrm{COOH}$ \\
\hline Benzaldehyde & $\mathrm{C}_{6} \mathrm{H}_{5} \mathrm{CHO}$ \\
\hline Salicylaldehyde & $\mathrm{C}_{6} \mathrm{H}_{4} \mathrm{CHO}-2-\mathrm{OH}$ \\
\hline Sulphuric acid & $\mathrm{H}_{2} \mathrm{SO}_{4}$ \\
\hline Nitric acid & $\mathrm{HNO}_{3}$ \\
\hline Hydrochloric acid & $\mathrm{HCl}$ \\
\hline Sodium hydroxide & $\mathrm{NaOH}$ \\
\hline Ammonium chloride & $\mathrm{NH}_{4} \mathrm{Cl}$ \\
\hline p-anisaldehyde & $\mathrm{CH}_{3} \mathrm{OC} \mathrm{H}_{4} \mathrm{CHO}$ \\
\hline Cinnamaldehyde & $\mathrm{C}_{6} \mathrm{H}_{5} \mathrm{CH}=\mathrm{CHCHO}$ \\
\hline Borneol & $\mathrm{C}_{10} \mathrm{H}_{18} \mathrm{O}$ \\
\hline Thymol & $\mathrm{C}_{10} \mathrm{H}_{14} \mathrm{O}$ \\
\hline 1,3 di-chloropropene & $\mathrm{C}_{3} \mathrm{H}_{4} \mathrm{Cl}_{2}$ \\
\hline Methyl bromide & $\mathrm{CH}_{3} \mathrm{Br}$ \\
\hline Ethylene dibromide & $\mathrm{C}_{2} \mathrm{H}_{4} \mathrm{Br}_{2}$ \\
\hline p-nitrophenol & $\mathrm{C}_{6} \mathrm{H}_{5} \mathrm{NO}_{3}$ \\
\hline Trinitrotoluene & $\mathrm{C}_{7} \mathrm{H}_{5} \mathrm{~N}_{3} \mathrm{O}_{6}$ \\
\hline
\end{tabular}

In context of the above the present work equivocally express the fact that-

- In control soil micro arthropods and their body parts, sting nematode, lesion nematode, nematode eggs, mites $\&$ ant population were found in the different layers of the collected soil. These organisms were not subjected to a chemical environment like that of the experimental soil. Also, nematode cyst, an indicator of adverse abiotic (in these case chemicals) / biotic conditions was also not being found.

- In experimental soil there is lack of micro arthropods, mites \& ant population. This indicates different chemicals listed in Table-1 affected survival \& distribution of these organisms as seen in different studies (Table-2) mentioned above.

There are also degenerated nematode eggs on the upper surface of the soil which probably is due to reaction with strong acids \& alkalis.

Lesion nematodes were not found in any depths of the collected soils probably due to presence of number of chemicals in the experimental soil (such as Benzaldehyde, Salicylaldehyde, Borneol, p-anisaldehyde, cinnamaldehyde etc) which inhibit population of lesion nematodes and their synergistic effect on them. Also, at a depth of 6 inches-12 inches, cysts of nematode were found indicating adverse conditions faced by the nematodes \& hence formation of cysts as a protective adaptation. Presence of lesion nematodes in both control \& experimental soil may indicate that the concentration of chemicals was too low to affect the population of lesion nematode or some other factor. Further analysis is needed in this regard. As for the change of soil fauna according to depth, it was seen that surface layer contained mostly nematode egg, arthropods and their body parts.

\section{ACKNOWLEDGEMENT}

I would like to express my deepest sense of gratitude to the Officer-in-Charge of A.B.N Seal College, Cooch Behar, West Bengal for always giving administrative support during laboratory work. I would also like to thank my undergraduate students for their overall cooperation during experimental works. Truly speaking this work is a culmination of group effort.

\section{REFERENCES}

[1] J.A. Wallwork. "The Distribution and Diversity of Soil Fauna", Academic Press, USA, pp.1-355, 1976.

[2] E. Scott, V. Kempster, K. Davies, "Chemical \& Biological induction of resistance to the clover cyst nematode (Heterodera trifolii) in white clover (Trifolium repens)". Nematology. Vol 3, Issue 1. pp. 35-43, 2001.

[3] J.E. Luc, W.T. Crow, J.L. Stimac, J.B. Sartain, G. Davis "Effects of Belonolaimus longicaudatus Management and Nitrogen Fertility 
on Turf Quality of Golf Course Fairways". Journal of Nematology. Vol.39. Issue 1.pp. 62-66, 2007.

[4] C. Calvet, J. Pinochet, A. Campburi "Evaluation of natural chemical compounds against root-lesion \& root-knot nematodes and side effects on infectivity of arbuscular mycorrhizal fungi". European Journal of Plant Pathology. Vol.107.Issue.6, pp. 601-605,2001.

[5] B.I. Hattar, W.I. Abu-Gharbieh, L. Al-Banna "Effect of elemental sulfur and sulfuric acid soil amendments on root-knot nematode and tomato growth in calcareous soils", Food and Agriculture Organization of the United Nations, In the database of National Centre for Agricultural Research \& amp Extension , pp. 23, 1988.

[6] J. Wang, J.P. Zhang, L. He , Z .M. Zhao"Influence of long-term exposure to simulated acid rain on development, reproduction and acaricide susceptibility of the carmine spider mite, Tetranychus cinnabarinus". Journal of Insect Science. pp. 6-19, 2006.

[7] R.W. Parmelee, R.S. Wentsel, C.T.Phillips, R.T.Checkai, M. Simini. "Soil microcosm for testing the effects of chemical pollutants on soil fauna communities and trophic structure". Environmental Toxicology and Chemistry: An International Journal Vol. 12.Issue.8, pp. 1477-1486, 1993.

[8] K. C. Ghose, B, Manna. "Practical Zoology" New Central Book Agency, Kolkata, India, pp. 503-507, 2015.

\section{Author Profile}

Sri Debojyoti Dutta pursued his graduation and Post graduation in Zoology from University of North Bengal. He Completed his M.Phil in Zoology from Annamalai University. He started his research work at Department of Zoology, Calcutta University but later shifted at National Institute for Research in Reproductive Health ( I C M R), Mumbai with ICMR genomic fellowship. He pursued $\mathrm{PhD}$ thesis on mtDNA related phylogenetic studies on Common toad. Besides handling a couple of UGC sponsored research projects, he published more than 23 original research articles in both National and International reputed journals and also more than 10 chapters in Books. His works are also submitted to NCBI database. He is the life member of Indian Science Congress Association, Indian Society of Cell Biology and Electron Microscopical Society of India. His research interests are in mitogenomics, Bioinformatics, Chronobiolgy etc. which are having both fields work as well as Laboratory work. 